\title{
Extracellular Signal-Regulated Kinase 2 (ERK2) Knockdown Mice Show Deficits in Long-Term Memory; ERK2 Has a Specific Function in Learning and Memory
}

\author{
Yasushi Satoh, ${ }^{1}$ Shogo Endo, ${ }^{5}$ Toshio Ikeda, ${ }^{6}$ Kazuyuki Yamada, ${ }^{7}$ Masataka Ito, ${ }^{2}$ Masahiko Kuroki, ${ }^{3}$ Takeshi Hiramoto, ${ }^{4}$ \\ Osamu Imamura, ${ }^{1}$ Yasushi Kobayashi, ${ }^{3}$ Yasuhiro Watanabe, ${ }^{4}$ Shigeyoshi Itohara, ${ }^{8}$ and Kunio Takishima ${ }^{1}$ \\ Departments of ${ }^{1}$ Biochemistry, ${ }^{2}$ Developmental Anatomy and Regenerative Biology, ${ }^{3}$ Anatomy and Neurobiology, and ${ }^{4}$ Pharmacology, National Defense \\ Medical College, Tokorozawa 359-8513, Japan, ${ }^{5}$ Unit for Molecular Neurobiology of Learning and Memory, Initial Research Project, Okinawa Institute of \\ Science and Technology, Uruma 904-2234, Japan, ${ }^{6}$ Laboratory of Experimental Animal Model Research, National Center for Geriatrics and Gerontology, \\ Morioka-machi, Obu 474-8511, Japan, and ${ }^{7}$ Research Resource Center and ${ }^{8}$ Laboratory for Behavioral Genetics, Brain Science Institute, RIKEN, Wako, \\ 351-0198, Japan
}

The extracellular signal-regulated kinase (ERK) 1 and 2 are important signaling components implicated in learning and memory. These isoforms display a high degree of sequence homology and share a similar substrate profile. However, recent findings suggest that these isoforms may have distinct roles: whereas ERK1 seems to be not so important for associative learning, ERK2 might be critically involved in learning and memory. Thus, the individual role of ERK2 has received considerable attention, although it is yet to be understood. Here, we have generated a series of mice in which ERK2 expression decreased in an allele dose-dependent manner. Null ERK2 knock-out mice were embryonic lethal, and the heterozygous mice were anatomically impaired. To gain a better understanding of the influence of ERK2 on learning and memory, we also generated knockdown mice in which ERK2 expression was partially (20-40\%) reduced. These mutant mice were viable and fertile with normal appearance. The mutant mice showed a deficit in long-term memory in classical fear conditioning, whereas short-term memory was normal. The mice also showed learning deficit in the water maze and the eight-arm radial maze. The ERK1 expression level of the knockdown mice was comparable with the wild-type control. Together, our results indicate a noncompensable role of ERK2-dependent signal transduction in learning and memory.

Key words: knock-out mice; extracellular signal-regulated kinase 2(ERK2); long-term memory; fear conditioning; water maze; eight-arm radial maze

\begin{abstract}
Introduction
Extracellular signal-regulated kinases (ERKs) are members of the mitogen-activated protein kinase (MAPK) superfamily and form a major signal transduction pathway mediating extracellular stimuli to the nucleus (Schaeffer and Weber, 1999). Originally discovered as regulators of cell division and differentiation, the major role of the ERK signaling pathway was also reported in synaptic plasticity, learning, and memory (Grewal et al., 1999; Impey et al., 1999; Sweatt, 2001, 2004; Mazzucchelli et al., 2002; Thomas and Huganir, 2004). For instance, ERK activation has been shown to be required for the induction of long-term potentiation (LTP) in the hippocampus (English and Sweatt, 1996;
\end{abstract}

\footnotetext{
Received Jan. 10, 2007; revised Aug. 2, 2007; accepted Aug. 3, 2007.

This study was in part performed with support from the Ministry of Education and Science of Japan (Y.S., S.E., K.T.). We thank Masako Suzuki for her excellent technical help and Dr. Kouichi Fukuda for his assistance in animal administration. We also thank Drs. Gilyana Borlikova and Toshiro Sakamoto for their critical reading of the previous draft of this manuscript.

Correspondence should be addressed to Dr. Kunio Takishima or Dr. Yasushi Satoh, Department of Biochemistry, National Defense Medical College, 3-2 Namiki, Tokorozawa 359-8513, Japan. E-mail: ktakishi@ndmc.ac.jp or ys@ndmc.ac.jp.

D0I:10.1523/JNEUROSCI.0117-07.2007

Copyright $\odot 2007$ Society for Neuroscience $\quad$ 0270-6474/07/2710765-12\$15.00/0
}

Atkins et al., 1998; Impey et al., 1998; Coogan et al., 1999; Winder et al., 1999; Wu et al., 1999; Kanterewicz et al., 2000; Watabe et al., 2000). Conversely, behavioral studies have also demonstrated an important role of ERK in long-term memory (Atkins et al., 1998; Blum et al., 1999; Selcher et al., 1999). These findings indicated an involvement of ERKs in the molecular events that were required at both the synaptic and behavioral levels, although no direct link proving a relationship between LTP and long-term memory has been shown.

ERK1 and ERK2 share 84\% of amino acid identity and have a very similar substrate profile (Boulton et al., 1991). In the analysis of ERK signaling, most experiments use MAPK kinase (MEK) inhibitors because no specific ERK inhibitor is available currently. ERK1 and ERK2 are solely activated by MEKs, and available MEK inhibitors do not differentiate between MEK isoforms, making it difficult to examine the specific contribution of each isoform to physiological functions. Thus, it is still remains unknown whether ERK1 and ERK2 redundantly share many brain functions and compensate for each other or whether they play distinctive roles. Under these circumstances, Selcher et al. (2001) demonstrated that ERK1 knock-out mice did not show significant impairment in learning. Furthermore, ERK1-deficient mice 
showed an enhancement of striatum-dependent long-term memory (Mazzucchelli et al., 2002). These results support the suggestion that ERK1 plays an accessory function to ERK2 (Adams and Sweatt, 2002), although the critical functions of ERK2 has not been yet directly proved because of the embryonic lethality of ERK2 null knock-out mice.

To study the function of ERK2, we used a gene-targeting technique to generate a series of ERK2 mutated alleles. The availability of viable and fertile ERK2 hypomorphic mutant mice allowed us to examine the consequence of reduced ERK2 in the behaviors. The mutant mice were impaired in fear conditioning when measured $48 \mathrm{~h}$ after training, although they appeared normal when measured $2 \mathrm{~h}$ after training. The mutant mice also showed learning impairment in the eight-arm radial maze task and slower learning in the Morris water maze task. Our results indicate that ERK2 but not ERK1 plays an essential role in long-term memory formation because ERK1 expression in the mutants remains unchanged. This may suggest a complicated and idiosyncratic involvement of ERK isoforms in the underlying cellular mechanisms of learning and memory.

\section{Materials and Methods}

\section{Generation of mutant mice}

The Erk2 gene was isolated from a 129/SvJ mouse genomic library (Sugiura et al., 1997). To generate the Erk2(floxN) allele, we constructed a targeting vector from $16.8 \mathrm{~kb}$ of Erk2 DNA (from the ApaI site in intron 1 to the TaqI in intron 6) (see Fig. 1A). For positive selection, a floxed (flanked by loxP sites) $P g k-n e o$ cassette was inserted in an inverted direction into the EcoRI site in intron 1. A third loxP site and KpnI and SapI sites were inserted into the BglII site in intron 3. The diphtheria toxin A fragment DNA (Yagi et al., 1993) was ligated to the 3 ' end of the vector. Homologous recombinants in 129-derived embryonic stem (ES) cell line E14 were identified by Southern blot analysis using $5^{\prime}$ and $3^{\prime}$ outer probes (data not shown). The confirmed clones were injected into blastocysts. The blastocysts were implanted into the uterus of pseudopregnant mice to yield chimeric mice. Offspring harboring the mutant allele was generated from crossing chimera mice with C57BL/6J mice and confirmed by Southern blot analysis using $5^{\prime}$ (see Fig. $1 A, B$ ) and $3^{\prime}$ outer probes (data not shown). Mice carrying the Erk2(floxN) allele were genotyped by PCR (see Fig. $1 \mathrm{~A}, \mathrm{C}$ ). The primers used were mE2-F2 (5' AAGGCTCACAGTGACAGTGACACC $3^{\prime}$ ) and mE2-R1 (5' CAGAGTTTCATTATGGAGTCCTCGC $3^{\prime}$ ) to detect the Erk2(floxN) allele and Erk2 wild-type allele. To delete Erk2, mice carrying the Erk2(floxN) allele were mated with EIIA-Cre mice (Xu et al., 2001). Original strain of EIIA-Cre mice were established in $\mathrm{FVB} / \mathrm{N}$, and the mice were backcrossed with $\mathrm{C} 57 \mathrm{BL} / 6$ for seven generations. Mice with Erk2 ${ }^{-}$were identified by Southern blot analysis (data not shown) and routinely genotyped by PCR using primers mE2-F2, mE2-R1, and mE2-F3 (5' GATCTGATGCTTGCCAAAGCC $\left.3^{\prime}\right)$.

All experiments were conducted according to the institutional ethical guidelines for animal experiments and safety guidelines for gene manipulation experiments of the National Defense Medical College, RIKEN, and Okinawa Institute of Science and Technology.

\section{Preparation of protein extracts}

After the animals were killed, the mouse brain was quickly removed from the skull, and cerebrum, cerebellum, and hippocampus were obtained. The obtained brain tissues were homogenized in 4 vol of $20 \mathrm{~mm}$ Tris- $\mathrm{HCl}$, pH 7.4, 2 mm EDTA, Complete Inhibitor Mix (Roche, Indianapolis, IN), and phosphatase inhibitors $\left(20 \mathrm{~mm}\right.$ glycerophosphate, $1 \mathrm{~mm} \mathrm{Na} \mathrm{VO}_{4}$, and $2 \mathrm{~mm} \mathrm{NaF}$ ). After homogenization, a portion of each sample was immediately frozen at $-80^{\circ} \mathrm{C}$. The rest of the homogenate was centrifuged at $15,000 \times g$ for $30 \mathrm{~min}$ at $4^{\circ} \mathrm{C}$. The supernatants were collected and stored at $-80^{\circ} \mathrm{C}$ until use. The amount of protein in each sample was measured using a MicroBCA assay (Pierce, Rockford, IL).
Western blot analysis

The supernatants of the homogenates were subjected to SDS-PAGE. The proteins in the SDS-PAGE gel were transferred onto an Immobilon-P membrane (Millipore, Bedford, MA). The blots were immunoreacted with anti-ERK1 (1:500; mouse monoclonal 6B11; Zymed Laboratories, South San Francisco, CA), anti-ERK2 (1:5000; mouse monoclonal 33; Transduction Laboratories, Lexington, KY), anti-ERK1/2 (1:1000; rabbit polyclonal 9102; Cell Signaling Technology, Beverly, MA), antiphospho-ERK2 (1:1000; rabbit polyclonal 9101; Cell Signaling Technology), or anti- $\beta$-actin (1:5000; mouse monoclonal AC-15; Sigma, St. Louis, MO) antibodies, and the protein bands were visualized by chemiluminescence detection system [Super Signal West Pico (Pierce) or ECL plus (GE Healthcare, Little Chalfont, UK)]. The signals in the immunoblots were analyzed by LAS3000 digital imaging system (Fujifilm, Tokyo, Japan).

\section{Histology}

While the animals were anesthetized with pentobarbital, they were perfused transcardially with heparinized PBS, $\mathrm{pH} 7.4$, and then $0.1 \mathrm{M}$ phosphate buffer containing 4\% paraformaldehyde. The brains and other organs were histologically analyzed using either frozen sections (40 $\mu \mathrm{m}$ thick) or paraffin-embedded sections (10 $\mu \mathrm{m}$ thick). Nissl and hematoxylin-eosin (HE) stains were performed according to standard procedures.

\section{Spine morphology}

The spine morphology of neurons in ERK2 knockdown mice was examined by using the lipophilic dye $1,1^{\prime}$-(dioctadecyl-3,3, $3^{\prime}, 3^{\prime}$ tetramethylindocarbocyanine perchlorate (DiI) (Invitrogen, Carlsbad, CA), which infiltrates the plasma membrane, labeling even the finest neuronal processes (Godement et al., 1987). DiI crystals were applied with a micropipette directly to microslice sections $(50 \mu \mathrm{m})$ set gently on top of an agar-filled Petri dish. The dish was then covered and stored at $4^{\circ} \mathrm{C}$ for $24-72 \mathrm{~h}$. Sections were mounted and coverslipped with Vectashield (Vector Laboratories, Burlingame, CA). $z$-axis stack images were acquired with a Nikon (Tokyo, Japan) C1 confocal microscope, which gave the possibility to assess the continuity of processes through the whole thickness of a tissue section. Mice used for the examination were 6 months of age.

\section{Behavioral analysis}

ERK2 hypomorphic mutant mice were backcrossed with C57BL/6J mice, and the resulting N9 to N11 offsprings were used for the experiments. Mice used for behavioral tests were obtained by intercrossing the heterozygous mice and consisted of age-matched male littermates (10-25 weeks of age). Mice used for open-field, elevated plus maze, Y-maze, and Morris water maze tests were the same set. Mice used for the eight-arm radial maze were reused for the fear conditioning test. Mice used for the home-cage activity test were reused for the wheel-running test. Mice were housed in groups of three to five (except for radial maze and homecage activity tests) under standard laboratory conditions with a $12 \mathrm{~h}$ light/dark (LD) cycle; room temperature was maintained at $23 \pm 1^{\circ} \mathrm{C}$. Mice had ad libitum access to water and food but were maintained on a restricted feeding schedule in an eight-arm radial maze test. All apparatus used in this study was made by O'Hara \& Company (Tokyo, Japan). Experimenters were blind to the genotypes of mice tested. The movement of each mouse was monitored and analyzed using a computeroperated video tracking system (SMART; Panlab, Barcelona, Spain). In the tasks using apparatus having arms, arm entry was counted when all four legs of an animal entered an arm. In the Y-maze, water maze, and eight-arm radial maze tasks, the apparatus were surrounded by prominent distal cues (e.g., big box, bench, and laboratory equipment) that were kept constant throughout training. The apparatus was cleaned with water after each trial.

\section{Open field}

Emotional responses to the novel environment were measured by an open-field test for 3 consecutive days. Mice were placed in an open-field $(50 \times 50 \times 40 \mathrm{~cm})$ chamber made of white acrylic for 10 min under 70 
lux lighting conditions. Activity was measured as the total distance traveled (meters). Mice used for the test were 11-13 weeks of age.

\section{Elevated plus maze}

The elevated plus maze consisted of two open arms $(25 \times 5 \mathrm{~cm})$ and two enclosed arms of the same size, with $15-\mathrm{cm}$-high transparent walls. The arms and central square were made of white acrylic plates and were elevated to a height of $50 \mathrm{~cm}$ above the floor. Arms of the same type were arranged on opposite sides to each other. Each mouse was placed in the central square of the maze $(5 \times 5 \mathrm{~cm})$, facing one of the open arms. Mouse behavior was recorded during a $10 \mathrm{~min}$ test period. The percentage of time spent in the open arms was used as an index of anxiety-like behavior. Mice used for the test were 11-13 weeks of age.

\section{Home-cage activity}

From $72 \mathrm{~h}$ before observations began, animals were housed individually in cages with bedding, food, and water. Activity was measured as the total distance traveled (meters) for $7 \mathrm{~d}$. Mice used for the test were 10-12 weeks of age.

\section{Spontaneous alternation in the Y-maze}

Spontaneous alternation was tested as described previously (Holcomb et al., 1998; Mishima et al., 2004; Ohno et al., 2004). This task does not involve any training, reward, or punishment and allowed us to assess spatial working memory, being based on the mouse's innate disposition to alternates. The symmetrical Y-maze made of acrylic consists of three arms $(25 \times 5 \mathrm{~cm})$ separated by $120^{\circ}$ with $15-\mathrm{cm}$-high transparent walls. Each mouse was placed in the center of the Y-maze, and the mouse was allowed to freely explore the maze for $8 \mathrm{~min}$. The sequence and the total number of arms entered were recorded. The percentage of alternation is the number of triads containing entries into all three arms divided by the maximum possible number of alternations (total number of arm entries -2$) \times 100$. Mice used for the test were 11-13 weeks of age.

\section{Water maze}

Spatial learning was assessed by the modified Morris water maze task (Morris, 1981; Morris et al., 1982; Dixon et al.; 1994). The water maze was a white tank ( $1.0 \mathrm{~m}$ diameter, $30 \mathrm{~cm}$ height) filled to a depth of $20 \mathrm{~cm}$ with water $\left(24 \pm 2^{\circ} \mathrm{C}\right)$, and white opaque nontoxic paint was added to the water to hinder visibility. A submerged Plexiglas platform $(10 \mathrm{~cm}$ diameter; $5 \mathrm{~mm}$ to $1 \mathrm{~cm}$ below the surface of the water) was located at a fixed position throughout training sessions. The position of the platform was varied from mouse to mouse while being counterbalanced across genotypes. One day before training (day 0), all mice were habituated to the maze. A training session consisted of a series of four trials per day for 14 consecutive days (total of 56 trials). The data were analyzed as days of four trials. In each trial, the mouse was placed into the tank at one of four designated start points in pseudorandom order. The mouse was given $60 \mathrm{~s}$ to find the submerged platform. If the mouse did not mount the platform within $60 \mathrm{~s}$, it was guided to the platform. The time to mount the platform was recorded as the training latency for each trial. Mice were allowed to remain on the platform for $30 \mathrm{~s}$ before being removed to a holding cage for a $1 \mathrm{~min}$ intertrial interval. A single probe trial, in which the platform was removed, was performed after the hidden platform task had been completed (day 15). Each mouse was placed into one quadrant of the pool and allowed to swim for $60 \mathrm{~s}$. Mice used for the test were 14-16 weeks of age at the start of the observation.

\section{Eight-arm radial maze}

The eight-arm radial maze task was conducted as described previously (Miyakawa et al., 2001). The mice were singly housed and gradually reduced to $80-85 \%$ of their free-feeding body weight. Throughout the experiment, they were maintained at their reduced weights by being fed a premeasured amount of chow each day. The apparatus consisted of eight arms $(25 \times 5 \mathrm{~cm})$ with $15-\mathrm{cm}$-high transparent walls. The arms and central arena were made of white plastic plates. The mice were first habituated to eat sweetened pellets (NOYES Precision pellets; Research Diets, New Brunswick, NJ) in all arms of the radial maze. Once all the mice were running freely through the maze and readily consuming the pellet rewards, training on the radial arm maze began. During training, arms were baited with one $20 \mathrm{mg}$ hidden food pellet each. A mouse was placed on the central platform and allowed to enter any of the eight arms to get food. Guillotine doors for all eight arms were shut down as soon as the mouse had visited one arm and returned to the central platform. The mouse was confined in the central arena for $10 \mathrm{~s}$ before the doors were reopened for the next arm choice. This $10 \mathrm{~s}$ delay forces the mouse to use spatial strategies to remember which arms have been visited instead of adopting a simpler serial searching strategy. A trial was terminated immediately after all pellets were consumed or $15 \mathrm{~min}$ had elapsed. The maze was rotated periodically to prevent the mice from using intramaze cues to solve the task.

$8-8$ version of eight-arm radial maze. Mice were trained on a radial maze task in which all arms were baited. Errors (working memory errors) were scored when a mouse entered an arm that had already been visited during the current trial. Mice received one trial per day for 12 consecutive days and 12 trials in total. Mice used for the test were 15-17 weeks of age at the start of the observation.

4-8 version of eight-arm radial maze. New groups of mice were used for this experiment. In this task, the same four of eight arms were baited, and the other four arms were never baited. The four baited arms were allocated such that two of these arms were adjacent, and the other arms were $90^{\circ}$ apart from these arms (e.g., arms 1, 3, 6, and 8) that were kept constant throughout the training. Reference memory errors were defined as entries into arms that were never baited, and working memory errors were scored as in the 8-8 version. Furthermore, the working memory error was subdivided into two types (Schmitt et al., 2003):"revisiting errors for baited arms" were scored when a mouse entered an arm that was baited but that had been visited in that trial, and "revisiting errors for unbaited arms" were scored when a mouse made repeated entries into an arm that was never baited. Mice received four trials with a $5 \mathrm{~min}$ intertrial interval per day for 16 consecutive days and 64 trials in total. The data were analyzed as days of four trials. Mice used for the test were 15-17 weeks of age at the start of the observation.

\section{Fear conditioning}

Fear conditioning was performed in a black plastic chamber equipped with a stainless steel grid floor. The chamber was mounted with a CCD camera, which was connected to a video monitor and computer. The grid floor was wired to a shock generator. An auditory signal was supplied from a loudspeaker. The conditioning (acquisition) trial for contextual and cued fear conditioning consisted of a 3 min exploration period followed by three conditioned stimulus (CS)-unconditioned stimulus (US) pairings separated by 1 min each (US, $1 \mathrm{~mA}$ footshock intensity, $1 \mathrm{~s}$ duration; CS, $84 \mathrm{db}$ white noise, $20 \mathrm{~s}$ duration; US was delivered during the last second of the CS presentation). A contextual test was performed in the conditioning chamber for $5 \mathrm{~min}$ in the absence of white noise at 2 or $48 \mathrm{~h}$ after conditioning. A cued test (for the same set of mice) was performed by presentation of the cue ( $84 \mathrm{db}$ white noise, 3 min duration) in an alternative context with distinct visual and tactile cues; the test chamber was different from the conditioning chamber in color (pale blue) and floor structure (no grid), and its floor was lined with chips. The cued test was conducted after the contextual test was finished. The rate of freezing response (total absence of movement except that required for respiration and heartbeat) of mice was used to measure the fear memory. The level of nonspecific freezing provoked by the new context was controlled for $3 \mathrm{~min}$ before the presentation of the cue in that new context. Mice used for the test were 23-25 weeks of age.

\section{Wheel running}

Mice for circadian rhythm analysis were housed individually in cages equipped with running wheels and maintained in the ventilated closets within a temperature- and humidity-controlled room under 300 lux lighting conditions. Water and food were available ad libitum. Mice were maintained on a $12 \mathrm{~h} \mathrm{LD}$ cycle before the study and for the first 2 weeks of activity monitoring. Running wheels were equipped with three holes on symmetrical sides, and activity was detected as beam (mounted on top of each cage) penetration through the holes. Ms. Circadian (Primelab, Tokyo, Japan) software was used to produce the double-plotted actograms as well as for periodogram. $\chi^{2}$ periodogram analysis was performed us- 
ing $28 \mathrm{~d}$ of data in constant darkness (DD). Mice used for the test were 16-18 weeks of age at the start of the observation.

\section{Statistics}

Statistical analysis was performed using Statview software (SAS, Cary, NC). Data were analyzed by Student's $t$ test, one-way ANOVA, or repeated-measures two-way ANOVA. In some analyses, ANOVA was followed by Fisher's PLSD post hoc tests. In the Y-maze task and probe test in the water maze, comparisons of group performance relative to random levels were performed using the one-sample $t$ test. Values are presented as the means \pm SEM.

\section{Results}

Lethality of $E r k 2^{-/-}$mice and semilethality of $E r k 2^{+/-}$mice To study the function of ERK2 in mice, we used gene targeting to generate a series of ERK2 alleles, including a null allele, a hypomorphic allele, and a conditional allele. We floxed the region containing the second and third exons of the ERK2 gene and neo-selection marker with three loxP sites (Fig. $1 A$ ) by homologous recombination in ES cells and derived germ-line targeted offspring (Erk2 floxN/+ mice). We excised these exons by introducing Cre recombinase. Targeted disruption of the ERK2 gene was confirmed by Southern blot analysis of genomic DNA from mouse tails (Fig. $1 B$ ). The complete loss of ERK2 $\left(E r k 2^{-/-}\right)$ caused very early embryonic lethality [approximately embryonic day 13.5 (E13.5)] in accordance with previous reports (Hatano et al., 2003; Saba-El-Leil et al., 2003). Mice heterozygous for the null allele $\left(E r k 2^{+/-}\right)$were not born in the Mendelian ratio expected from intercrosses of heterozygotes (14 of 167; 8.4\%). Moreover, they had a smaller body mass compared with their wild-type littermates (our unpublished observations).

\section{Hypomorphic Erk2(floxN) allele}

Western blot analysis revealed that ERK2 protein expression levels in the brains of the generated cell lines were incrementally reduced: $E r k 2^{+/+}>E r k 2^{\text {floxN/+ }}>E r k 2^{\text {floxN/floxN }}$ (Fig. 2A-C). Although the expression of ERK2 in Erk $2^{\text {floxN/floxN }}$ mice was reduced, it recovered to normal levels after excision of the neo cassette by in vivo crossing with transgenic mice expressing Cre recombinase (data not shown). Thus, the Erk2(floxN) allele generated was a hypomorphic allele because of the presence of a $P g k-n e o$ cassette inserted in its 5' untranslated region (Fig. 1A). Erk $2^{\text {floxN/floxN }}$ mice were born at the expected Mendelian ratio from intercrosses of heterozygotes ( 62 of $258 ; 24.0 \%$ ). Using the combination of Erk2 $2^{+/-}$and Erk2 $2^{\text {floxN/+ }}$ mice, we tried to generate $E r k 2^{\text {floxN/- }}$ mice; however, this caused embryonic lethality at approximately E13.5 similar to Erk2 ${ }^{-/-}$mice.

\section{Hypomorphic ERK2 mice show unaltered ERK1 expression}

We analyzed the expression profile of some proteins in the mutant mice brain. In 1-month-old mice, ERK2 expressions were significantly reduced in the hippocampus and cerebellum of mutant mice (Fig. 2A,C) (ANOVA; hippocampus, $F_{(2,15)}=13.78$, $p<0.0005$; cerebellum, $\left.F_{(2,15)}=10.44, p<0.005\right)$. Although the mean value of ERK2 expressions in the cerebrum (without hippocampus) of mutant mice was reduced, it was not statistically significant (Fig. $2 A, C$ ) (ANOVA, $F_{(2,15)}=3.40, p>0.05$ ). In 12-month-old mice, ERK2 expressions were also reduced in the hippocampus, cerebellum, and cerebrum of mutant mice (Fig. $2 B, C$ ) (ANOVA; cerebrum, $F_{(2,21)}=5.25, p<0.05$; hippocampus, $F_{(2,21)}=14.73, p=0.0001$; cerebellum, $F_{(2,21)}=36.27, p<$ $0.0001)$

To check for possible compensatory changes of ERK1 expression in ERK2 knockdown mice, we assessed the protein expres-
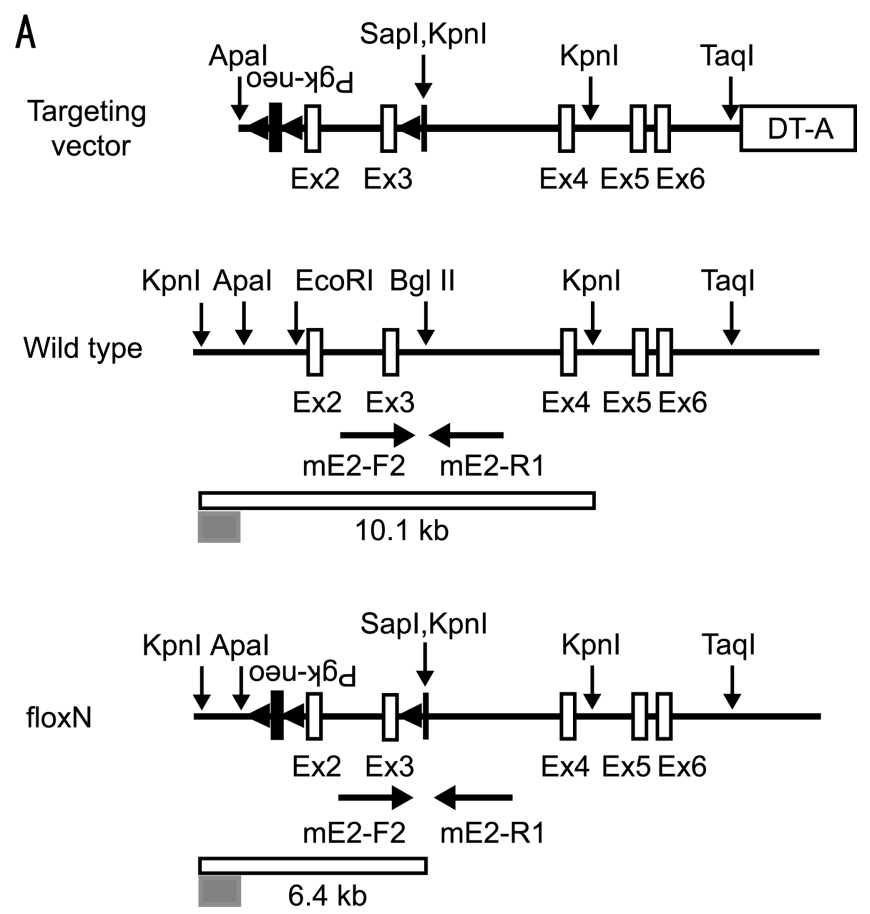

B

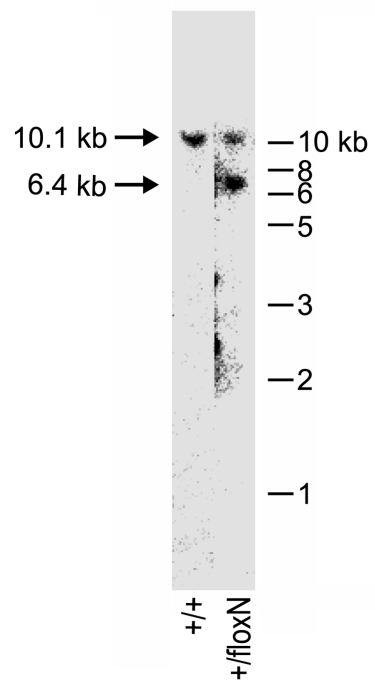

c

Figure 1. Schematic diagram of targeted knockdown of the mouse Erk2 gene. $A$, The targeting vector (top), wild-type Erk2 allele (middle), and Erk2(floxN) allele (bottom). White boxes represent Erk2 exons (Ex), and black boxes represent the Pgk-neo cassette. A Kpnl restriction site was generated in intron 3 (black bar). The 5' outer probes used for Southern blot analysis are shown as gray boxes. The primers used for PCR are shown as arrows. $\boldsymbol{B}$, Southern blot analysis of wild-type and heterozygous adult mice genomic DNA. DNA samples were digested with Kpnl and hybridized with the $5^{\prime}$ outer probe. The positions and sizes of wild-type and mutant fragments are indicated. C, PCR genotyping of wild-type and homozygous mice. The positions and sizes of $P C R$ fragments for wild-type and mutant mice are indicated.

sion level of ERK1. We found no differences in ERK1 expression between ERK2 mutant and wild-type mouse brains in both 1- and 12-month-old mice (Fig. $2 A, B, D$ ) (ANOVA, all $p$ values $>0.05$ ). We also evaluated the in vivo activation state of ERK2 in brain extracts with antibodies against phospho-ERK. The difference in ERK2 phosphorylation levels between wild-type and mutant mice in the basal state was not statistically significant (Fig. 


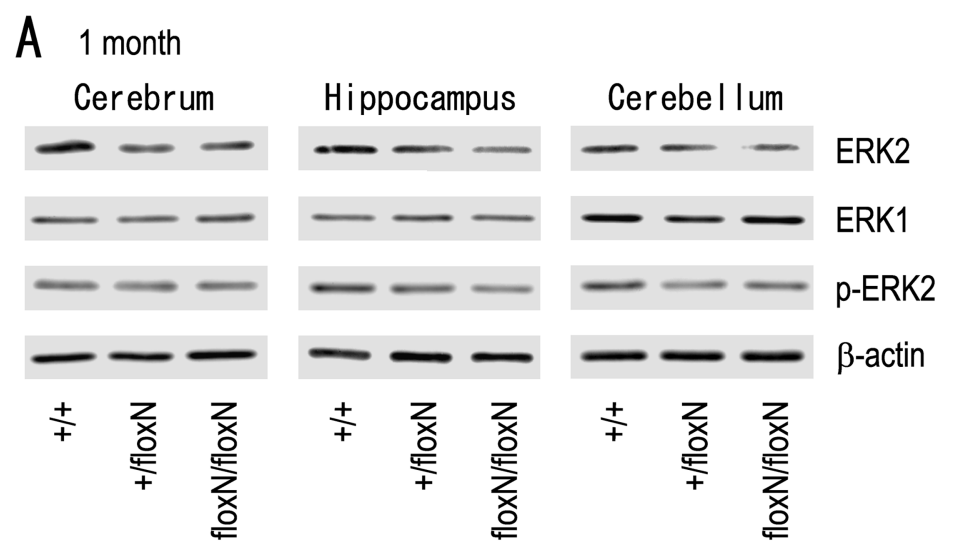

B 12 month

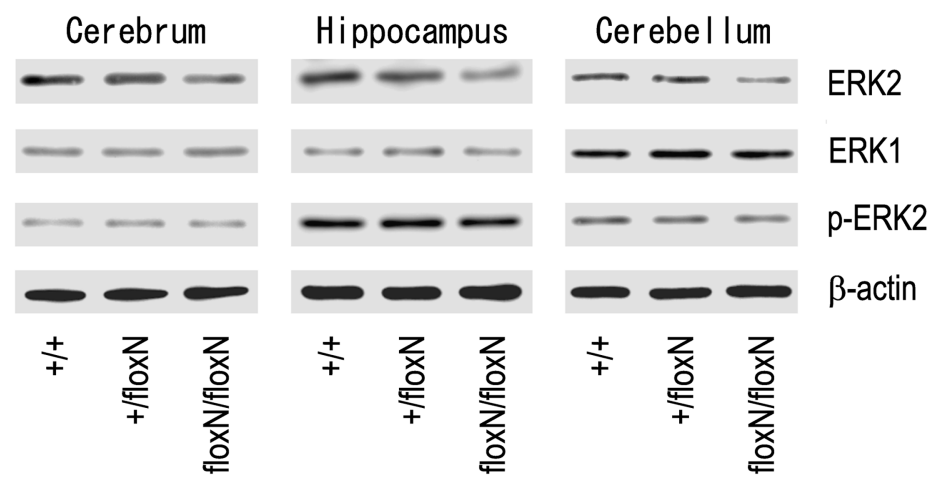

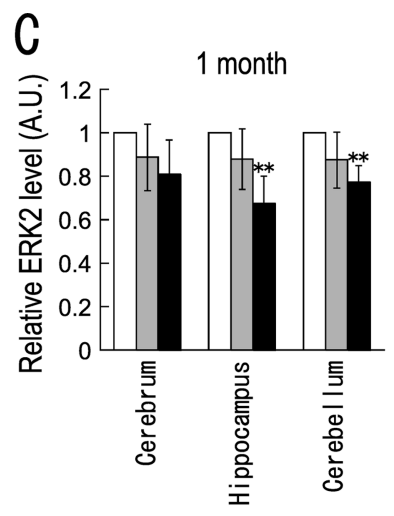
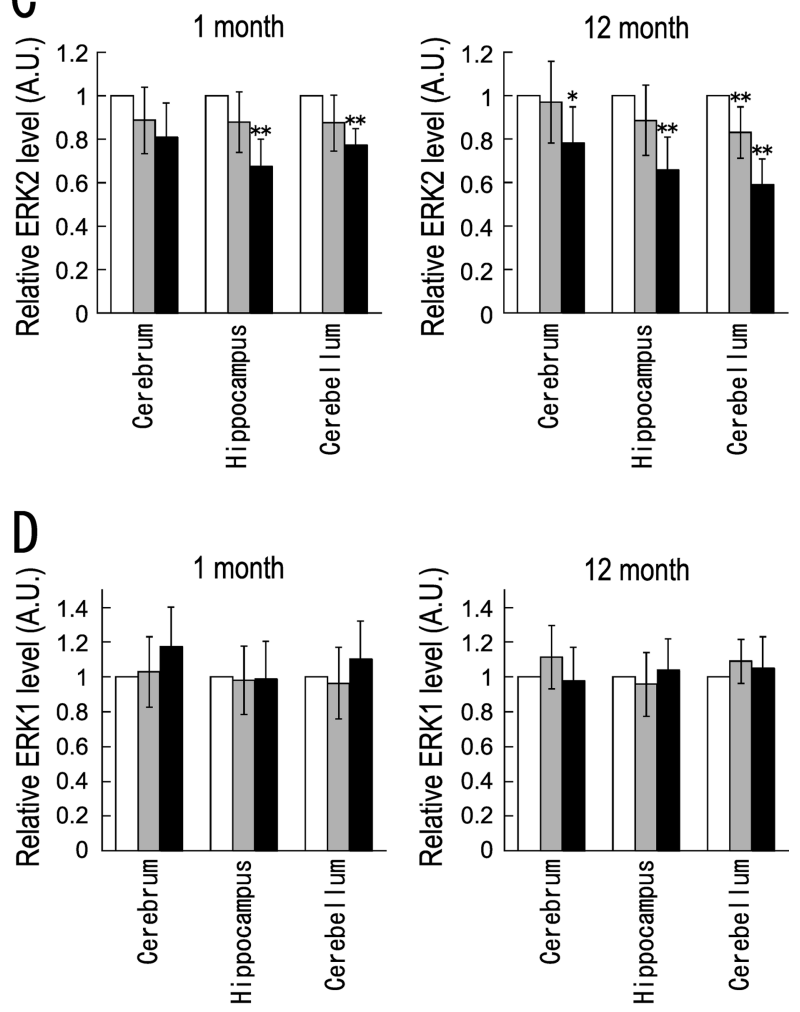

$\mathrm{E}$
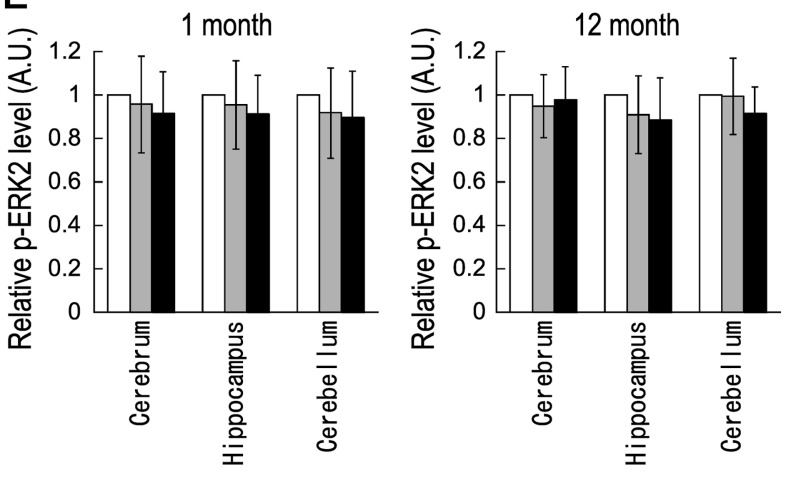

$\square+/+\quad \square$ floxN/+

floxN/floxN

Figure 2. Western blot analysis of Erk2 ${ }^{+1+}, E r k 2^{\text {floxN/+}}$, and Erk2 $2^{\text {floxN/floxN }}$ mice. $\boldsymbol{A}, \boldsymbol{B}$, Expressions of ERK2, ERK1, phospho-ERK2, and $\beta$-actin in an extract obtained from the cerebrum, hippocampus, and cerebellum from 1-month-old $(\boldsymbol{A})$ or 12 -month-old $(\boldsymbol{B})$ mice. The gels shown are representative examples. $\boldsymbol{\beta}$-Actin served as controls for protein loading. $\boldsymbol{C}-\boldsymbol{E}$, The graphs depict the averaged results from eight (1 month of age) or six (12 months of age) experiments. ${ }^{*} p<0.05 ;{ }^{* *} p<0.01$.

$2 A, B, E)$ (ANOVA, all $p$ values $>0.05)$, although ERK2 phosphorylation seemed slightly decreased in mutant mice.

\section{Apparent normal histology of Erk $2^{\text {floxN/floxN }}$ and Erk $2^{\text {floxN/+ }}$ mice}

Before examining the possible effects of ERK2 reduction on synaptic function in vivo, we analyzed the brains and other organs of mutant mice for anatomical abnormalities. We did not observe any abnormalities of $E r k 2^{\text {floxN/+ }}$ and $E r k 2^{\text {floxN/floxN }}$ mice in overall health, appearance, and body weight at 8 months of age $\left(E r k 2^{+/+}, 33.9 \pm 4.0 \mathrm{~g} ;\right.$ Erk2 $^{\text {floxN/+}}, 32.5 \pm 3.7 \mathrm{~g} ;$ Erk2 $2^{\text {floxN/floxN }}$, $32.1 \pm 4.4 \mathrm{~g}$; ANOVA, $\left.F_{(2,41)}=0.93, p>0.05\right)$. To examine the possible effects of mutation on tissue structures, we performed an extensive histological survey of the body. Although a wide variety of tissue, including the lung, liver, kidney, heart, thymus, and spleen, from 6-week-old, 6-month-old, and 15-month-old mice were examined with HE staining, no significant differences were detected between $E r k 2^{\text {floxN/floxN }}$ and wild-type littermates (data not shown).

Detailed histological analysis of Erk $2^{\text {floxN/floxN }}$ mouse brains with HE staining did not reveal any gross differences from those of wildtype littermates. We did not also find any signs of increased cell death by detecting pyknotic nuclei in Nissl-stained sections (Fig. 3A-D). The neocortex showed a normal layered structure, and cortical neurons had a normal appearance based on neuronal-specific nuclear protein NeuN, GFAP, and TuJ staining (data not shown). These results suggest that Erk2 ${ }^{\text {floxN/floxN }}$ and Erk $2^{\text {floxN/+ }}$ mice appeared to develop without gross morphological defects and had a minimal effect on hippocampal architecture and cell/neurite density at least at the light-microscopic level. 

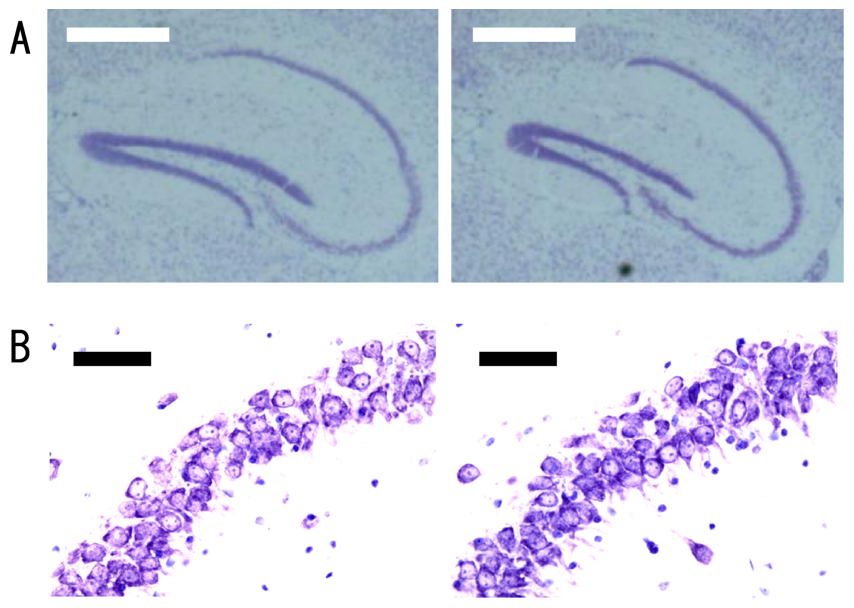

C
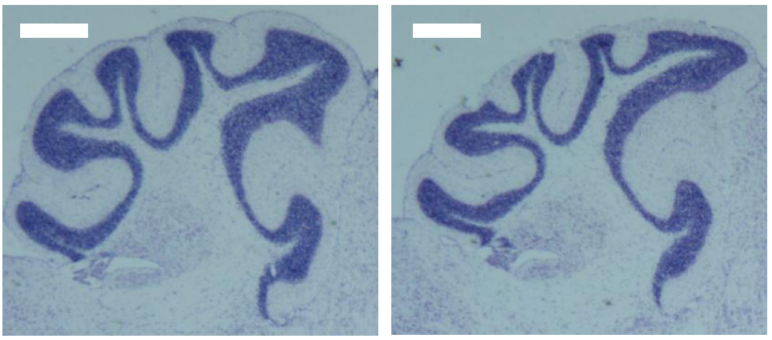

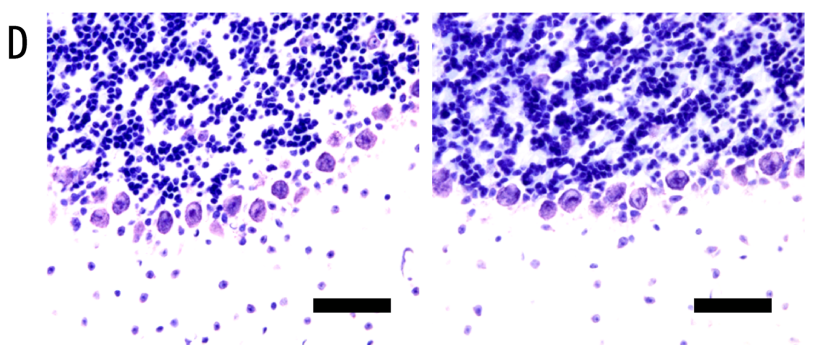

$+/+$
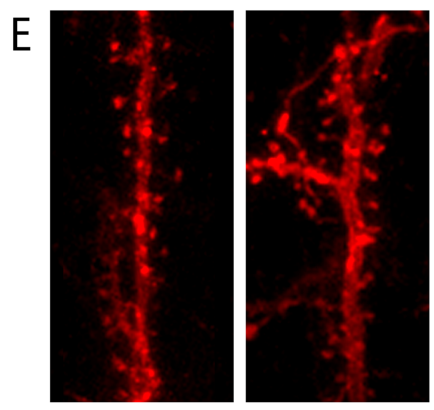

$+/+$
floxN/floxN
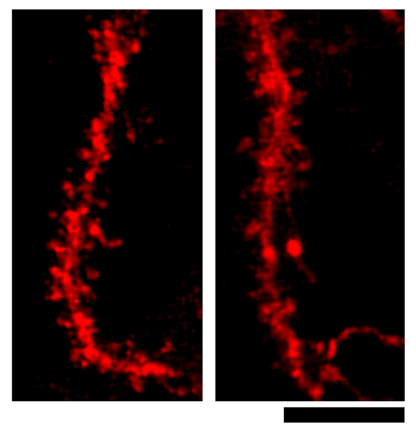

floxN/floxN

Figure 3. ERK2 knockdown mice showed normal histology in the brain. $\boldsymbol{A}-\boldsymbol{D}$, Nissl staining of hippocampus $(\boldsymbol{A})$, pyramidal layer of hippocampus $(\boldsymbol{B})$, cerebellum $(\boldsymbol{C})$, and Purkinje layer of cerebellum (D).E, Synaptic density in ERK2 knockdown mice was not altered. Representative dendritic segments of dentate gyrus neurons from Erk2 ${ }^{+/+}$(left) and Erk2 ${ }^{\text {floxN/floxN }}$ (right) mice. Scale bars: $A, C, 500 \mu \mathrm{m} ; \boldsymbol{B}, \mathbf{D}, 50 \mu \mathrm{m} ; \boldsymbol{E}, 10 \mu \mathrm{m}$.

\section{Spine morphology}

ERK may regulate synaptic remodeling (Kornhauser and Greenberg, 1997; Wu et al., 2001; Goldin and Segal, 2003). Specifically, the formation and stabilization of dendritic spines via ERK is believed to be involved in long-term information storage in the CNS (Sweatt, 2004). Thus, we set out to examine the developmental effect of ERK2 knockdown on spine morphology in the hippocampal area CA1, CA3, dentate gyrus, and cortical layer II/III. To examine the number of dendritic spines at the basal level, we used the lipophilic tracer DiI. DiI staining showed that the number of spines per $10 \mu \mathrm{m}$ dendritic segment was not altered in the dentate gyrus from $E r k 2^{\text {floxN/floxN }}$ and wild-type mice (Fig. $3 E)\left(E r k 2^{+/+}, 7.18 \pm 0.77, n=10\right.$ neurons from 3 mice; Erk $2^{\text {floxN/floxN }}, 7.51 \pm 0.84, n=10$ neurons from 3 mice; $t$ test, $p>0.05)$. There was also no significant difference in other regions (data not shown).

\section{General behavior of Erk $2^{\text {floxN/+ }}$ and $E r k 2^{\text {floxN/floxN }}$ mice}

To examine responses to a novel environment, Erk2 ${ }^{+1+}$, $E r k 2^{\text {floxN/+ }}$, and Erk $2^{\text {floxN/floxN }}$ mice were assayed in an openfield test for 3 consecutive days. The mutant mice did not differ from Erk2 $2^{+/+}$control animals in their exploratory behavior (Fig. $4 A$ ) (ANOVA, all $p$ values $>0.05$ ).

To study whether ERK2 knockdown affected anxiety-related behavior, Erk2 ${ }^{+/+}, E r k 2^{\text {floxN/+ }}$, and $E r k 2^{\text {floxN/floxN }}$ mice were subjected to an elevated plus maze test. These mice did not differ significantly in the percentage of time spent in the open arms $($ Fig. $4 B)\left(\right.$ ANOVA, $\left.F_{(2,39)}=0.27, p>0.05\right)$. These results indicate that the emotional state of the mutant mice did not differ from wild-type littermates under the conditions used.

To examine spontaneous activities, Erk2 ${ }^{+/+}$and $E r k 2^{\text {floxN/floxN }}$ mice were assayed in their home cages. The mutant mice showed no difference from wild type in ambulation
$\left(E r k 2^{+/+}, 1945 \pm 477 \mathrm{~m}, n=10 ; E r k 2^{\text {floxN/floxN }}, 2174 \pm 314 \mathrm{~m}\right.$, $n=10$; $t$ test, $t=1.06, p>0.05)$. To examine the behavioral rhythmicity, we monitored wheel-running activity under DD for 4 weeks, after an initial $14 \mathrm{~d}$ in a $12 \mathrm{~h} \mathrm{LD} \mathrm{cycle.} \mathrm{Erk2}{ }^{+/+}$and Erk2 $2^{\text {floxN/floxN }}$ mice did not differ significantly in the circadian periods of behavior (Fig. $4 D, E)\left(E r k 2^{+/+}, 23.95 \pm 0.17 \mathrm{~h}, n=6\right.$; $E r k 2^{\text {floxN/floxN }}, 23.91 \pm 0.19 \mathrm{~h}, n=7$; $t$ test, $\left.t=0.39, p>0.05\right)$. All Erk $2^{\text {floxN/floxN }}$ mice tested displayed strong behavioral rhythmicity throughout the 4 weeks in $\mathrm{DD}$, comparable with wild-type mice (Fig. $4 D, E$ ).

\section{Y-maze}

To examine whether ERK2 knockdown was associated with changes in spatial working memory, mice were subjected to a Y-maze spontaneous alternation task. This test examines whether mice remember the position of the arm selected in the preceding choice. $E r k 2^{+/+}, E r k 2^{\text {floxN/+ }}$, and $E r k 2^{\text {floxN/floxN }}$ mice performed this task by means of $61.2-64.1 \%$ correct choices, which were well above the random choice (random choice, $50 \%$; one-sample $t$ test, all $p$ values $>0.05$ ), and there was no difference among these mice (Fig. $4 C$ ) (ANOVA, $F_{(2,32)}=0.21, p>0.05$ ). This result suggests that spatial working memory was normal in ERK2 knockdown mice.

\section{Fear conditioning}

It was reported that preventing ERK activation with an MEK inhibitor impaired pavlovian fear learning in mice (Atkins et al., 1998; Schafe et al., 1999; Selcher et al., 1999). To assess the influence of ERK2 knockdown on long-term and short-term memory, Erk2 $2^{+/+}$and Erk2 floxN/floxN mice were subjected to contextual/ cued fear conditioning. In this paradigm, mice learn to associate previous neutral auditory cues and the apparatus (context) with electric footshock in a single training session, and robust long- 

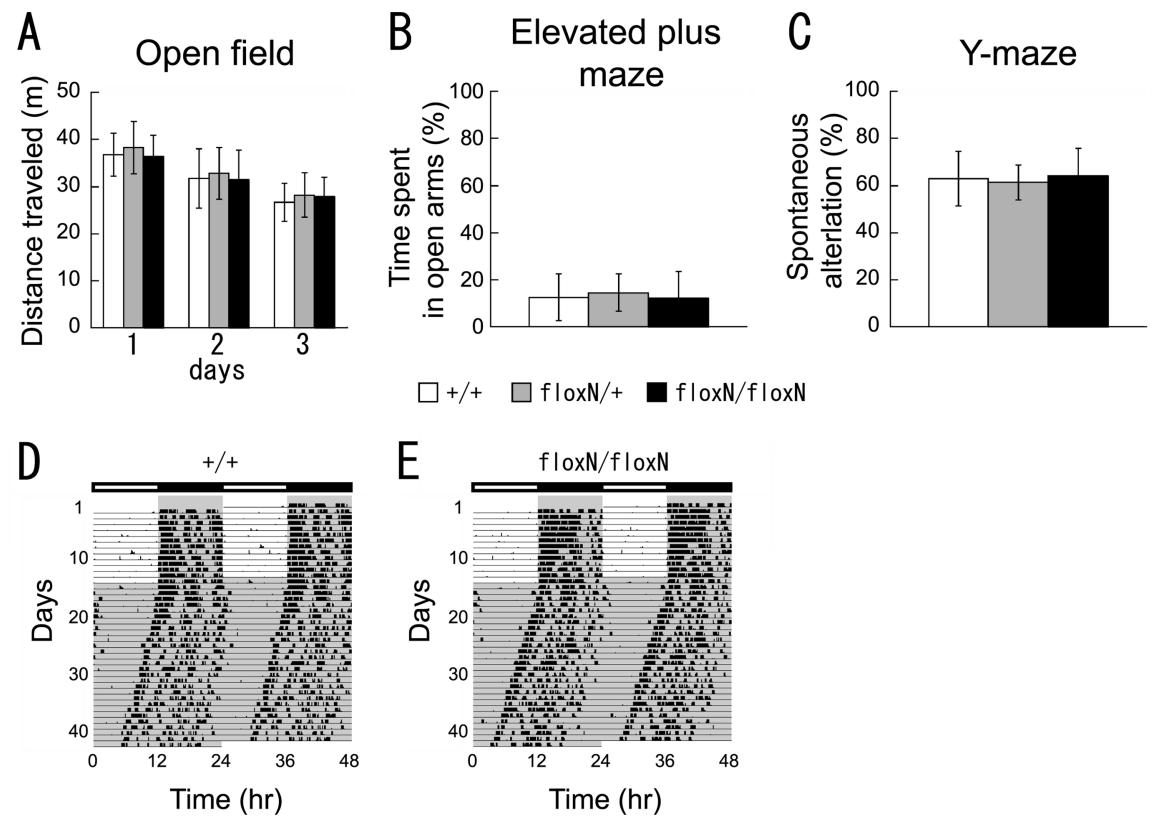

Figure 4. ERK2 knockdown mice showed normal behavior in the open-field, elevated plus maze, Y-maze, and wheel-running tests. $\boldsymbol{A}$, Open-field test (total distance traveled in $10 \mathrm{~min}$ for 3 consecutive days, Erk2 ${ }^{+/+}, n=12$; Erk $2^{\text {floxN/+}}, n=11$; Erk2 $^{\text {floxN/floxN }}, n=12$ ). B. Elevated plus maze test (percentage time spent in open arms, Erk2 ${ }^{+/+}, n=12$; Erk2 ${ }^{\text {floxN N/+ }}, n=16$; Erk2 ${ }^{\text {floxN/floxN }}, n=12$ ). C, Y-maze test (percentage correct alternation response). No significant differences were observed between wild-type and ERK2 knockdown mice in these tests (Erk2 ${ }^{+++}, n=12$; Erk2 $\left.2^{\text {floxN/+}}, n=11 ; E_{\text {Erk2 }}{ }^{\text {floxN/floxN }}, n=12\right)$. D, $\boldsymbol{E}$, Representative actograms in wheel-running test for Erk2 ${ }^{+/+}(\boldsymbol{D})$ and Erk2 ${ }^{\text {floxN/floxN }}(\boldsymbol{E})$ mice in double-plotted format. Each horizontal line represents $48 \mathrm{~h}$. Vertical bars represent periods of wheel-running activity. Animals were initially housed in $12 \mathrm{~h} \mathrm{LD}$ cycle for $14 \mathrm{~d}$ and then were transferred to DD. The LD cycle is indicated by the bar above the top records. Numbers on the left indicate days of study.

term memory is established for an experimental context (hippocampus-dependent) and an auditory cue (hippocampusindependent) (Kim and Fanselow, 1992; Phillips and LeDoux, 1992). Long-term and short-term memory was assessed based on the freezing reaction of a mouse in response to the conditioned cue or the context. The freezing response of Erk $2^{\text {floxN/floxN }}$ mice was the same as control mice in the conditioned chamber without cues (contextual fear) after $2 \mathrm{~h}$ retention delay (Fig. $5 \mathrm{~A}$ ) ( $t$ test, $t=$ $0.16, p>0.05)$. Conversely, the response of mutant mice was reduced significantly compared with the control after $48 \mathrm{~h}$ retention delay (Fig. $5 B$ ) ( $t$ test, $t=4.17, p<0.0005)$. The response of mutant mice to the continued cue was also reduced significantly after $48 \mathrm{~h}$ retention delay compared with wild-type mice (Fig. $5 \mathrm{C}$ ) ( $t$ test, $t=7.54, p<0.0001$ ). The deficit in the conditioned freezing observed suggests that ERK2 has an important role in long-term memory in classical fear conditioning, although shortterm memory is not vulnerable to ERK2 depletion.

Furthermore, the ERK2 activations during fear conditioning were examined between Erk2 $2^{+/+}$and Erk2 floxN/floxN mice by Western blot analysis using antibody for the phosphorylated ERK. Hippocampal phospho-ERK2 levels in both Erk2 ${ }^{+/+}$and $E r k 2^{\text {floxN/floxN }}$ mice significantly increased $1 \mathrm{~h}$ after the training compared with control mice without footshock (Fig. 5D) $\left(\right.$ Erk $^{+/+}, t$ test $, t=7.30, p<0.005 ; E r k 2^{\text {floxN/floxN }}, t$ test, $t=3.95$, $p<0.005)$. However, the phospho-ERK2 level in $E r k 2^{\text {floxN/floxN }}$ mice was lower than that in Erk2 ${ }^{+/+}$mice (Fig. $5 D, E)$ ( $t$ test, $t=2.81, p<0.05)$. The expression levels of ERK2 both in $E r k 2^{+/+}$and Erk2 floxN/floxN mice were not altered by Western blot analysis before and after the training (data not shown). The signal ratio of phospho-ERK2 to ERK2 in $E r k 2^{\text {floxN/floxN }}$ mice was 1.3-fold higher than that in Erk $2^{+/+}$mice before the training $\left(E r k 2^{\text {floxN/floxN }}, 1.34 \pm\right.$ $0.25, n=5$; the values are normalized by the ratio for $E r k 2^{+/+}$), indicating that basal ERK2 phosphorylation is increased in the mutants but became comparable after the training $\left(E r k 2^{+/+}, 2.95 \pm 0.39, n=\right.$ $5 ; E r k 2^{\text {floxN/floxN }}, 2.88 \pm 0.61, n=5 ; t$ test, $t=0.20, p>0.05$; the values are normalized by the ratio for $E r k 2^{+/+}$before the training). These results indicate that the activation status of ERK2 is almost the same between Erk $2^{\text {floxN/floxN }}$ and Erk $2^{+/+}$ mice after the training and that the reduced phospho-ERK2 level of Erk2 ${ }^{\text {floxN/floxN }}$ mice seems to be a critical factor for the deficit in long-term memory in fear conditioning.

\section{Morris water maze}

To assess spatial long-term memory in ERK2 knockdown mice, we studied the performance of Erk2 $2^{+/+}$and Erk $2^{\text {floxN/floxN }}$ mice in the hiddenplatform version of the Morris water maze test (Morris, 1981). This task is a hippocampus-dependent cognitive task that requires spatial memory (Morris et al., 1982). As shown in Figure 6A, although both Erk2 $2^{+/+}$and Erk2 floxN/floxN mice progressively learned to escape as training proceeded, the mean escape latencies of $E r k 2^{\text {floxN/floxN }}$ mice were significantly longer than those of wild-type littermates (retardation). Two-factor repeated ANOVA revealed a significant main effect of genotype (ANOVA, $F_{(1,22)}=24.25, p<0.0001$ ), a significant main effect of day (ANOVA, $F_{(13,286)}=30.31, p<0.0001$ ), and a genotype by day interaction (ANOVA, $F_{(13,286)}=2.68, p<$ $0.005)$. Additional analysis indicated significant genotype differences on days 2-7 and day 9. After day 10, statistical significances between the genotypes were no longer seen. Figure $6, B$ and $C$, shows representative swim paths for $E r k 2^{\text {floxN/floxN }}$ mice and wild-type mice, respectively, on the fifth day of training. On the final day, a single probe test was performed, in which the platform was removed to assess whether the animals remembered the location of the platform and whether they used a nonspatial strategy to find the platform. During the probe trial, mutant mice search specifically in the former platform quadrant $\left(E r k 2^{\text {floxN/floxN }}, 38.8 \pm 9.6 \%\right.$; chance level, $25 \%$; $t$ test, $t=4.05$, $p<0.005)$ as well as control mice $\left(E r k 2^{+/+}, 39.1 \pm 10.5 \%\right.$; chance level, 25\%; $t$ test, $t=3.60, p<0.005)$. These results suggest that Erk $2^{\text {floxN/floxN }}$ mice had retarded spatial learning, although eventually they reached the same performance level as control animals. The results of the probe trial confirm the absence of differences between experimental groups in spatial memory formed by the end of water maze training.

\section{Eight-arm radial maze}

To further characterize the impairment of hippocampusdependent spatial memory, Erk2 ${ }^{+/+}$and Erk2 floxN/floxN mice were subjected to the eight-arm radial maze task (Olton and Samuelson, 1976; Olton et al., 1979). This task, similar to the Morris water maze, has been shown to depend on hippocampal function (Olton, 1987; Rossi-Arnaud and Ammassari-Teule, 1998) but is 
less stressful than the Morris water maze test, which requires an escape response. The eight-arm radial maze consists of eight arms radiating from a central arena and mice collect hidden rewards of food located at the ends of arms, using distal extramaze cues around the apparatus. The concept of distinct working memory and a reference memory system was developed by Olton and colleagues from studies using the radial arm maze (Olton and Samuelson, 1976; Olton et al., 1979). In the present study, we referred to the reference memory as incremental learning memory that occurs over multiple trials, leading to the formation of constant memory across trials, whereas working memory was referred to as one-trial learning, leading to the formation of trial-specific memory, which requires not only within-trial acquisition but also the suppression of between-trial interference in the eightarm radial maze. In each trial, mice must visit each of the eight arms only once to consume the food rewards most effectively because the revisiting arm is not rewarded. Thus, the mice have to remember which arms they have already visited. Such a revisit to a previously visited arm in one trial was counted as a working memory error. First, we tested the 8-8 version of the eightarm radial maze. This paradigm can mostly assess the capacity of spatial working memory by measuring whether the animals can remember a sequence of previously visited feeding sites, although this task also requires reference memory to some extent because a mouse has to learn how to apply it across trials. Analysis of the latency to perform the task in each trial showed that mutant mice required a longer time than wild-type mice in early training days but finally achieved the same performance as wild-type mice (Fig. 7A). Two-way repeated ANOVA of the latencies revealed a significant main effect of the genotype $\left(F_{(1,26)}=4.28, p<0.05\right)$, a significant main effect of day $\left(F_{(11,286)}=\right.$ $87.87, p<0.0001)$, and a genotype by day interaction $\left(F_{(11,286)}=9.77, p<0.0001\right) . t$ test indicated significant genotype differences on days 3 and 4 . On day 5 , statistical differences between the genotypes were no longer seen, and both genotypes apparently reached a learning plateau. This indicates that all mice learned the 8-8 radial maze, although the mutants showed poorer learning compared with wild-type mice up to day 5. Two-way repeated ANOVA of correct choices during the first eight choices revealed a significant main effect of day $\left(F_{(1,26)}=\right.$ 20.32, $p<0.05)$; however, there is no significant main effect of the genotype $\left(F_{(11,286)}=0.70, p>0.05\right)$ and genotype by day interaction $\left(F_{(11,286)}=1.39, p>0.05\right)($ Fig. $7 B)$. This also indicates that all mice could learn the 8-8 radial maze. Two-way repeated ANOVA of total working memory errors (total number of revisiting errors) revealed a significant main effect of the genotype $\left(F_{(1,26)}=4.89, p<0.05\right)$, a significant main effect of day $\left(F_{(11,286)}=34.24, p<0.0001\right)$, and a genotype by day interaction $\left(F_{(11,286)}=5.35, p<0.0001\right)$ (Fig. $\left.7 C\right)$. The $t$ test indicated significant genotype differences on days $2-4$. On day 5, statistical differences between the genotypes were no longer seen, and both genotypes apparently reached a learning plateau. Comparison of the total number of revisiting errors (Fig. 7C) with the number of correct arm choices during the first eight trials (Fig. $7 B$ ) indicated that the mutant mice committed more errors during their attempts to find the one or two last arms still containing bait on days 2-4; however, the number of revisiting errors for the mutant mice approached the same level as for wild-type mice after day 5, suggesting that the working memory of mutant mice was not critically impaired. 
A
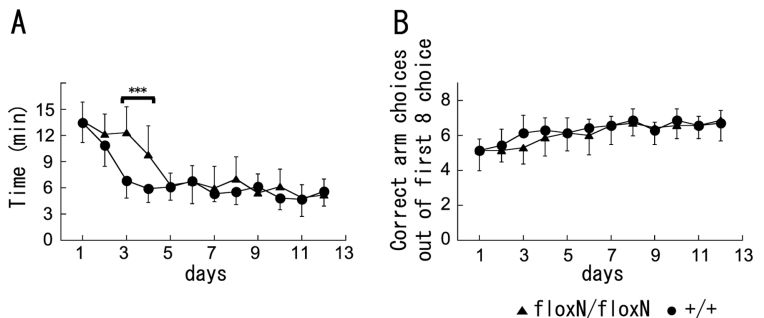

C

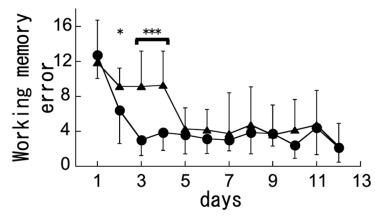

Figure 7. ERK2 knockdown mice were partially impaired in the 8-8 version (8 arms fully baited) eight-arm radial maze task $A-C$, Mice were trained in one trial per day for 12 consecutive days and 12 trials. Learning performance is expressed as the mean latency $(\boldsymbol{A})$, the mean number of correct (distinct) arm choices during the first eight trials $(\boldsymbol{B})$, and total number of revisiting errors (C). ERK2 knockdown mice required a longer time to complete a trial on days 3 and 4 , but, on day 5 , statistical differences between genotypes were no longer seen and both genotypes apparently reached a learning plateau $(\boldsymbol{A})$. ERK2 knockdown mice showed no significant genotype effect in correct choices (during the first 8 trials) $(\boldsymbol{B})$ and made higher error scores only from days 2 to 4 ( $(\boldsymbol{C})$ $\left(\right.$ Erk2 ${ }^{+/+}, n=14 ;$ Erk2 $\left.^{\text {floxN/floxN }}, n=14\right) .{ }^{*} p<0.05 ;{ }^{* * *} p<0.001$.
A
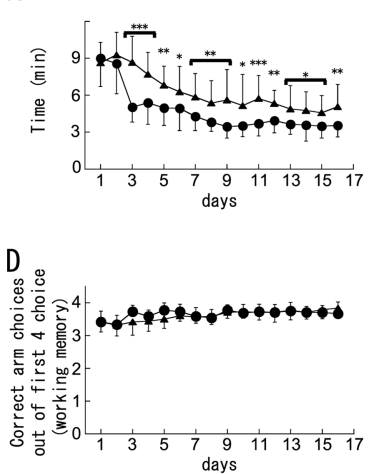

B

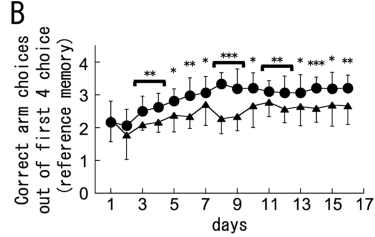

$\mathrm{E}$

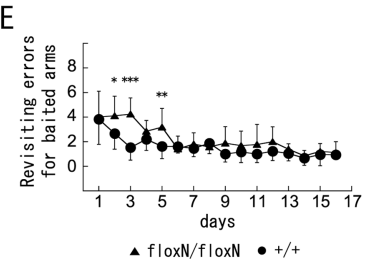

C

$\mathrm{F}$

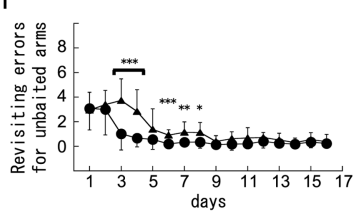

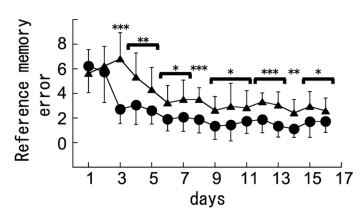

Figure 8. ERK2 knockdown mice showed impaired reference memory in learning in the 4-8 version (only 4 arms baited) of the eight-arm radial maze task. Mice were trained for four trials per day for 16 consecutive days and 64 trials. $A$, ERK2 knockdown mice required a longer time and did not reach the wild-type curve. $B, C$, As a measure of reference memory, learning performance is expressed as the mean number of correct (baited) arm choices during the first four trials $(\boldsymbol{B})$ and total number of visiting errors of never baited arms (C). ERK2 knockdown mice showed fewer reference memory correct choices $(\boldsymbol{B})$ and higher error scores $(\boldsymbol{C})$ throughout the experiment; however, in the same task, working memory error was not critically impaired. $\boldsymbol{D}$, As a measure of working memory, correct (distinct) choices (during the first 4 choices) were almost the same as the control. $\boldsymbol{E}, \boldsymbol{F}$, Total number of revisiting errors for baited arms $(\boldsymbol{E})$ or revisiting errors for unbaited arms $(\boldsymbol{F})$ shows that the curve of ERK 2 knockdown mice reached that of wild-type mice (after days 6 and 9 , respectively) although the mutant mice had significantly higher scores in reference memory errors (Erk2 ${ }^{+/+}, n=12 ;$ Erk2 $\left.^{\text {floxN/floxN }}, n=12\right) .{ }^{*} p<0.05 ;{ }^{* *} p<0.01 ;{ }^{* * *} p<0.001$.

Second, another set of mice was trained by the $4-8$ version of the eight-arm radial maze, in which only four of eight arms, but always the same arms, were baited. This task requires learning the arms baited over multiple trials, leading to the formation of constant memory across trials (reference memory) in addition to the working memory. Thus, this version allows us to assess working memory and reference memory at the same time and dissociates these memories not only within subjects but also within the same trial (Schmitt et al., 2003). Two-way repeated ANOVA of latencies revealed a significant main effect of genotype $\left(F_{(1,22)}=16.80\right.$, $p=0.0005)$, a significant main effect of day $\left(F_{(15,330)}=43.85, p<\right.$ $0.0001)$, and significant genotype by day interaction $\left(F_{(15,330)}=\right.$ $2.26, p<0.005$ ) (Fig. 8A). Analysis of reference memory correct choices during the first four choices in each trial revealed significantly lower correct scores for mutant mice compared with littermate controls (Fig. $8 B$ ). Two-way repeated ANOVA revealed a significant main effect of genotype $\left(F_{(1,22)}=22.88, p=0.0001\right)$, main effect of day $\left(F_{(15,330)}=11.82, p<0.0001\right)$, and significant genotype by day interaction $\left(F_{(15,330)}=1.88, p<0.05\right)$. Analysis of the reference memory error scores (total number of visiting errors of never baited arms) also showed significantly higher scores in the mutants compared with wildtype mice (Fig. 8C). Two-way repeated ANOVA revealed a significant main effect of the genotype $\left(F_{(1,22)}=29.81, p<\right.$ $0.0001)$ and main effect of day $\left(F_{(15,330)}=\right.$ $24.96, p<0.0001$ ) (Fig. 8C). Figure $8 A-C$ shows that, although the increase in correct choices was significant in mutant mice, they showed significantly poorer learning of the baited arms even on day 16. The increase in correct choices demonstrates that the mice used a spatial searching strategy rather than a nonspatial serial searching strategy.

Conversely, analysis of the correct choices of working memory during the first four choices revealed that the mutant mice had almost intact spatial memory in the 4-8 version of the eight-arm radial maze similar to the case in Figure $7 B$ (Fig. $8 D)$. Two-way repeated ANOVA revealed a significant main effect of day $\left(F_{(15,330)}=\right.$ $6.12, p<0.0001)$; there was, however, no main effect of genotype $\left(F_{(1,22)}=1.67, p>\right.$ $0.05)$ and no genotype by day interaction $\left(F_{(15,330)}=1.39, p>0.05\right)$. Figure $8 D$ shows that mutant and wild-type mice made similar numbers of different arm choices during the first four choices, demonstrating that the mutants did not have pronounced motivational impairment. Furthermore, to analyze the profile of the working memory error, it was subdivided into revisiting errors for baited arms and revisiting errors for unbaited arms. In terms of revisiting errors for baited arms, there was a significant main effect of genotype $\left(F_{(1,22)}=15.24, p<0.001\right)$, main effect of day $\left(F_{(15,330)}=18.35, p<0.0001\right)$, and significant genotype by day interaction $\left(F_{(15,330)}=3.15, p<0.0001\right)$ (Fig. $8 E) . t$ test indicated significant genotype differences on days 2, 3, and 5. On day 6, statistical differences between the genotypes were no longer seen, and both genotypes apparently reached a learning plateau. Analysis of revisiting errors for unbaited arms revealed a significant main effect of genotype $\left(F_{(1,22)}=24.46, p<0.0001\right)$, a main effect of day $\left(F_{(15,330)}=\right.$ $28.22, p<0.0001)$, and a significant genotype by day interaction $\left(F_{(15,330)}=4.09, p<0.0001\right)$ (Fig. $\left.8 F\right) . t$ test indicated significant genotype differences on days 3,4 , and $6-8$. Figure $8, E$ and $F$, shows that the mutants did not commit significantly more errors (total errors of working memory) compared with wild-type mice after days 6 and 9, respectively, although the mutant committed more reference memory errors (Fig. $8 \mathrm{C}$ ), demonstrating that reference memory errors were unaffected by revisiting errors for baited arms or revisiting errors for unbaited arms in this phase and vice versa. As a whole, the spatial working memory required to perform the eight-arm radial maze task does not seem to be critically affected by the knockdown of ERK2, although there seemed to be learning retardation. Conversely, reference memory was impaired in the ERK2 knockdown mice, although a certain degree of reference memory appeared to be present. 


\section{Discussion}

In this study, we generated lines of ERK2 mutant mice, including ERK2 knockdown and knock-out mice, and found that ERK2 knockdown mice were impaired in some type of cognitive tasks, especially in those that needed long-term memory formation. This suggests that the ERK2 amount is critical for demanding tasks and that ERK2 is an essential component for long-term memory.

In the present study, we revealed the significant effects of the ERK2 reduction on the mice behaviors, although the reduction of the ERK2 protein expression level of mutant mice was relatively small. In contrast, the knock-out of ERK1 has been reported to result in a stimulus-dependent increase of ERK2 signaling at the cellular level and an enhancement of striatum-dependent longterm memory instead of memory impairment (Mazzucchelli et al., 2002). Thus, our results clearly point to some important differences between the functions of ERK1 and ERK2 in learning and memory.

The possible reasons for the predominant function of ERK2 in learning and memory may be attributable to specific activation by upstream kinases. In fact, several groups reported that glutamate receptor activation followed by PKC activation leads to selective ERK2 activation (Bading and Greenberg, 1991; Fiore et al., 1993; English and Sweatt, 1996, 1997). However, this is unlikely because purified MEK1 phosphorylates and activates ERK1 and ERK2 with similar kinetics (Zheng and Guan, 1993). Another explanation is that ERK1 and ERK2 have distinct neuronal distributions in the brain; for example, ERK2 may be more abundant in the hippocampus than ERK1. Additional investigation is necessary to establish the role of ERK2 in learning and memory, and use of our knockdown mice is suitable for this purpose to overcome both the embryonic lethality of ERK2 knock-out mice and the nonspecific inhibition of ERK isoforms by MEK inhibitors.

Our analysis of fear conditioning revealed that long-term memory was impaired in Erk $2^{\text {floxN/floxN }}$ mutant mice, whereas short-term memory looked normal, consistent with previous studies showing that MEK inhibitor blocks long-term memory in fear conditioning (Atkins et al., 1998; Schafe et al., 1999; Selcher et al., 1999). The impairment of the long-term memory observed in the cued fear conditioning suggests that the deficits are not restricted to the hippocampus-dependent tasks (Fig. 5C). Moreover, reference memory impairment in ERK2 knockdown mice was demonstrated in the radial maze study (Fig. 8C). This impairment might be simply caused by a loss of either or both the establishment of long-term spatial memory with visual cues and learning how to use the cues. Meanwhile, the results in the Morris water maze test are more complicated. The mutant mice initially exhibited some learning retardation, and then the learning curve approached that of wild-type mice after repetitive practices, indicating that some long-term memory was formed in $E r k 2^{\text {floxN/floxN }}$ mutant mice. Erk $2^{\text {floxN/floxN }}$ mice may need prolonged training for long-term memory, especially in stressful conditions such as the water maze task. The retarded learning in water maze task might continue to be prominent in the less demanding situation of radial maze, in which mice do not have high motivation to eliminate visits to the unbaited arms because it does not affect their ability to retrieve food substantially. No alteration between the mutant and control mice was observed in the probe test after the final training of the water maze test, indicating that the mutant mice did use spatial strategies at the final training. However, it is possible for the mutant mice to have used a nonspatial strategy in the earlier phase of learning, resulted in spending more time to learn the task.

Another possible explanation for the retarded learning is that it is caused by the impairment of some selective process of memory stages. Memory can be experimentally divided into several stages, including acquisition, consolidation, retrieval, reconsolidation, and extinction (Abel and Lattal, 2001; Nader, 2003; Suzuki et al., 2004). In the Morris water maze task, repeated retrieval and reconsolidation during training are thought to stabilize spatial reference memory. The reduced amount of ERK2 may cause the deficit in the reconsolidation system and lead to the retarded learning of the mutant mice in the water maze. Indeed, the inhibition of the ERK pathway is known to block reconsolidation in object recognition and fear conditioning tasks (Kelly et al., 2003; Cestari et al., 2006). It is also known that experimental conditions are important determinants of whether reconsolidation or extinction occurs after a reactivation, which may explain the divergent results on the learning curve between the water maze and radial maze tasks (Tronson and Taylor, 2007).

We analyzed working memory of the mutants in two different tasks, radial maze and Y-maze. Analysis of the fully or partially baited eight-arm radial maze task showed the working memory impairment in the early phase of training in ERK2 knockdown mice (Figs. 7C, 8E,F). Conversely, no deficit was observed in spontaneous alternation in Y-maze task. The eight-arm radial maze test uses the bait as a reinforcer and is more complicated compared with the Y-maze task. Consequently, the mice likely need a few days to learn the rules of task. This "rule learning" process, similar to the process to form the reference memory, is considered to be independent of working memory. The Y-maze does not require rule learning, and mutant mice might give similar results to wild-type mice. Thus, the working memory deficits observed in the early training period of the radial maze may not be the true working memory errors but may be a slower rule learning in these animals.

ERK2 knockdown mice showed no significant change in the basal levels of phosphorylated ERK2, although it appeared to be slightly reduced compared with wild-type control. One explanation for these data are that the ratio of phosphorylated to unphosphorylated ERK2 at the basal level is generally very low and the reduction dosage in ERK2 knockdown mice might not cause a significant decrease of the basal ERK2 phosphorylation level. However, stimulation in fear conditioning made a significant difference in the phosphorylation level of ERK2 between the knockdown mice and the wild-type control. The learning deficits in Erk2 $2^{\text {floxN/floxN }}$ mice may thus be much attributable to the reduced levels of training-induced ERK2 phosphorylation.

Embryonic lethality as observed in Erk2 ${ }^{-/-}$and Erk2 floxN/mutant mice might suggest a critical threshold of ERK2 expression for survival. It is possible that mice could compensate to survive the relatively subtle reduction of ERK2 but were overcome more severe depletion in Erk2 $2^{-/-}$and Erk2 ${ }^{\text {floxN/- }}$ mutant mice. Our results showed the existence of the dose dependency of ERK2 for the survival. The lethality of ERK2 knockdown mice points to important differences between ERK1 and ERK2 because ERK1 knock-out mice are viable and appear normal (Pagès et al., 1999). The cause of death remains to be investigated, but it was reported that ERK2 has an essential role in placental development (Hatano et al., 2003) or trophoblast development (Saba-El-Leil et al., 2003).

In conclusion, $E r k 2^{-1-}$ and Erk2 floxN/- mice were embryonic lethal and $E r k 2^{+/-}$was semilethal. Conversely, hypomorphic $E r k 2^{\text {floxN/floxN }}$ knockdown mice enabled us to assess the impor- 
tance of ERK2 in cognitive performance. ERK2 knockdown mice were not compensated for in learning and memory, suggesting that ERK2, but not ERK1, may have a predominant role in learning and memory. Because behavioral changes are associated with the partially reduced expression of ERK2, the dosage of ERK2 may be closely related to cognitive function. Future work using Cre-mediated recombination will shed additional light on the mechanisms and on neural pathways that require ERK2 signaling during learning and memory formation.

\section{References}

Abel T, Lattal KM (2001) Molecular mechanisms of memory acquisition, consolidation and retrieval. Curr Opin Neurobiol 11:180-187.

Adams JP, Sweatt JD (2002) Molecular psychology: roles for the ERK MAP kinase cascade in memory. Annu Rev Pharmacol Toxicol 42:135-163.

Atkins CM, Selcher JC, Petraitis JJ, Trzaskos JM, Sweatt JD (1998) The MAPK cascade is required for mammalian associative learning. Nat Neurosci 1:602-609.

Bading H, Greenberg ME (1991) Stimulation of protein tyrosine phosphorylation by NMDA receptor activation. Science 253:912-914.

Blum S, Moore AN, Adams F, Dash PK (1999) A mitogen-activated protein kinase cascade in the CA1/CA2 subfield of the dorsal hippocampus is essential for long-term spatial memory. J Neurosci 19:3535-3544.

Boulton TG, Nye SH, Robbins DJ, Ip NY, Radziejewska E, Morgenbesser SD, DePinho RA, Panayotatos N, Cobb MH, Yancopoulos GD (1991) ERKs: a family of protein-serine/threonine kinases that are activated and tyrosine phosphorylated in response to insulin and NGF. Cell 65:663-675.

Cestari V, Costanzi M, Castellano C, Rossi-Arnaud C (2006) A role for ERK2 in reconsolidation of fear memories in mice. Neurobiol Learn Mem 86:133-143.

Coogan AN, O'Leary DM, O'Connor JJ (1999) P42/44 MAP kinase inhibitor PD98059 attenuates multiple forms of synaptic plasticity in rat dentate gyrus in vitro. J Neurophysiol 81:103-110.

Dixon CE, Hamm RJ, Taft WC, Hayes RL (1994) Increased anticholinergic sensitivity following closed skull impact and controlled cortical impact traumatic brain injury in the rat. J Neurotrauma 11:275-287.

English JD, Sweatt JD (1996) Activation of p42 mitogen-activated protein kinase in hippocampal long term potentiation. J Biol Chem 271:24329-24332.

English JD, Sweatt JD (1997) A requirement for the mitogen-activated protein kinase cascade in hippocampal long term potentiation. J Biol Chem 272:19103-19106.

Fiore RS, Murphy TH, Sanghera JS, Pelech SL, Baraban JM (1993) Activation of $\mathrm{p} 42$ mitogen-activated protein kinase by glutamate receptor stimulation in rat primary cortical cultures. J Neurochem 61:1626-1633.

Godement P, Vanselow J, Thanos S, Bonhoeffer F (1987) A study in developing visual systems with a new method of staining neurons and their processes in fixed tissue. Development 101:697-713.

Goldin M, Segal M (2003) Protein kinase C and ERK involvement in dendritic spine plasticity in cultured rodent hippocampal neurons. Eur J Neurosci 17:2529-2539.

Grewal SS, York RD, Stork PJ (1999) Extracellular-signal-regulated kinase signaling in neurons. Curr Opin Neurobiol 9:544-553.

Hatano N, Mori Y, Oh-hora M, Kosugi A, Fujikawa T, Nakai N, Niwa H, Miyazaki J, Hamaoka T, Ogata M (2003) Essential role for ERK2 mitogen-activated protein kinase in placental development. Genes Cells 11:847-856.

Holcomb L, Gordon MN, McGowan E, Yu X, Benkovic S, Jantzen P, Wright K, Saad I, Mueller R, Morgan D, Sanders S, Zehr C, O'Campo K, Hardy J, Prada CM, Eckman C, Younkin S, Hsiao K, Duff K (1998) Accelerated Alzheimer-type phenotype in transgenic mice carrying both mutant amyloid precursor protein and presenilin 1 transgenes. Nat Med 4:97-100.

Impey S, Obrietan K, Wong ST, Poser S, Yano S, Wayman G, Deloulme JC, Chan G, Storm DR (1998) Cross talk between ERK and PKA is required for $\mathrm{Ca}^{2+}$ stimulation of CREB-dependent transcription and ERK nuclear translocation. Neuron 21:869-883.

Impey S, Obrietan K, Storm DR (1999) Making new connections: role of ERK/MAP kinase signaling in neuronal plasticity. Neuron 23:11-14.
Kanterewicz BI, Urban NN, McMahon DB, Norman ED, Giffen LJ, Favata MF, Scherle PA, Trzskos JM, Barrionuevo G, Klann E (2000) The extracellular signal-regulated kinase cascade is required for NMDA receptorindependent LTP in area CA1 but not area CA3 of the hippocampus. J Neurosci 20:3057-3066.

Kelly A, Laroche S, Davis S (2003) Activation of mitogen-activated protein kinase/extracellular signal-regulated kinase in hippocampal circuitry is required for consolidation and reconsolidation of recognition memory. J Neurosci 23:5354-5360.

Kim JJ, Fanselow MS (1992) Modality-specific retrograde amnesia of fear. Science 256:675-677.

Kornhauser JM, Greenberg ME (1997) A kinase to remember: dual roles for MAP kinase in long-term memory. Neuron 6:839-842.

Mazzucchelli C, Vantaggiato C, Ciamei A, Fasano S, Pakhotin P, Krezel W, Welzl H, Wolfer D, Pagès G, Valverde O (2002) Knockout of ERK1 MAP kinase enhances synaptic plasticity in the striatum and facilitates striatal-mediated learning and memory. Neuron 34:807-820.

Mishima K, Tanoue A, Tsuda M, Hasebe N, Fukue Y, Egashira N, Takano Y, Kamiya HO, Tsujimoto G, Iwasaki K, Fujiwara M (2004) Characteristics of behavioral abnormalities in alpha1d-adrenoceptors deficient mice. Behav Brain Res 152:365-373.

Miyakawa T, Yamada M, Duttaroy A, Wess J (2001) Hyperactivity and intact hippocampus-dependent learning in mice lacking the $\mathrm{M}_{1}$ muscarinic acetylcholine receptor. J Neurosci 21:5239-5250.

Morris RG (1981) Spatial localization does not depend on the presence of local cues. Learn Motiv 12:239-260.

Morris RG, Garrud P, Rawlins JN, O’Keefe J (1982) Place navigation impaired in rats with hippocampal lesions. Nature 297:681-683.

Nader K (2003) Memory traces unbound. Trends Neurosci 26:65-72.

Ohno M, Sametsky EA, Younkin LH, Oakley H, Younkin SG, Citron M, Vassar R, Disterhoft JF (2004) BACE1 deficiency rescues memory deficits and cholinergic dysfunction in a mouse model of Alzheimer's disease. Neuron 41:27-33.

Olton DS (1987) The radial arm maze as a tool in behavioral pharmacology. Physiol Behav 40:793-797.

Olton DS, Samuelson RJ (1976) Remembrance of places passed: Spatial memory in rats. J Exp Psychol Anim Behav Process 2:97-116.

Olton DS, Becker JT, Handelmann GH (1979) Hippocampus, space and memory. Behav Brain Sci 2:313-365.

Pagès G, Guerin S, Grall D, Bonino F, Smith A, Anjuere F, Auberger P, Pouyssegur J (1999) Defective thymocyte maturation in p44 MAP kinase (Erk 1) knockout mice. Science 286:1374-1377.

Phillips RG, LeDoux JE (1992) Differential contribution of amygdala and hippocampus to cued and contextual fear conditioning. Behav Neurosci 106:274-285.

Rossi-Arnaud C, Ammassari-Teule M (1998) What do comparative studies of inbred mice add to current investigations on the neural basis of spatial behaviors? Exp Brain Res 123:36-44.

Saba-El-Leil MK, Vella FD, Vernay B, Voisin L, Chen L, Labrecque N, Ang SL, Meloche S (2003) An essential function of the mitogen-activated protein kinase Erk2 in mouse trophoblast development. EMBO Rep 4:964-968.

Schaeffer HJ, Weber MJ (1999) Mitogen-activated protein kinases: specific messages from ubiquitous messengers. Mol Cell Biol 19:2435-2444.

Schafe GE, Nadel NV, Sullivan GM, Harris A, LeDoux JE (1999) Memory consolidation for contextual and auditory fear conditioning is dependent on protein synthesis, PKA, and MAP kinase. Learn Mem 6:97-110.

Schmitt WB, Deacon RM, Seeburg PH, Rawlins JN, Bannerman DM (2003) A within-subjects, within-task demonstration of intact spatial reference memory and impaired spatial working memory in glutamate receptor-Adeficient mice. J Neurosci 23:3953-3959.

Selcher JC, Atkins CM, Trzaskos JM, Paylor R, Sweatt JD (1999) A necessity for MAP kinase activation in mammalian spatial learning. Learn Mem 6:478-490.

Selcher JC, Nekrasova T, Paylor R, Landreth GE, Sweatt JD (2001) Mice lacking the ERK1 isoform of MAP kinase are unimpaired in emotional learning. Learn Mem 8:11-19.

Sugiura N, Suga T, Ozeki Y, Mamiya G, Takishima K (1997) The mouse extracellular signal-regulated kinase 2 gene. Gene structure and characterization of the promoter. J Biol Chem 272:21575-21581.

Suzuki A, Josselyn SA, Frankland PW, Masushige S, Silva AJ, Kida S (2004) 
Memory reconsolidation and extinction have distinct temporal and biochemical signatures. J Neurosci 24:4787-4795.

Sweatt JD (2001) The neuronal MAP kinase cascade: a biochemical signal integration system subserving synaptic plasticity and memory. J Neurochem 76:1-10.

Sweatt JD (2004) Mitogen-activated protein kinases in synaptic plasticity and memory. Curr Opin Neurobiol 14:311-317.

Thomas GM, Huganir RL (2004) MAPK cascade signaling and synaptic plasticity. Nat Rev Neurosci 5:173-183.

Tronson NC, Taylor JR (2007) Molecular mechanisms of memory reconsolidation. Nat Rev Neurosci 8:262-275.

Watabe AM, Zaki PA, O’Dell TJ (2000) Coactivation of $\beta$-adrenergic and cholinergic receptors enhances the induction of long-term potentiation and synergistically activates mitogen-activated protein kinase in the hippocampal CA1 region. J Neurosci 20:5924-5931.

Winder DG, Martin KC, Muzzio IA, Rohrer D, Chruscinski A, Kobilka B, Kandel ER (1999) ERK plays a regulatory role in induction of LTP by theta frequency stimulation and its modulation by beta-adrenergic receptors. Neuron 24:715-726.

Wu GY, Deisseroth K, Tsien RW (2001) Spaced stimuli stabilize MAPK pathway activation and its effects on dendritic morphology. Nat Neurosci 4:151-158.

Wu SP, Lu KT, Chang WC, Gean PW (1999) Involvement of mitogenactivated protein kinase in hippocampal long-term potentiation. J Biomed Sci 6:409-417.

Xu X, Li C, Garrett-Beal L, Larson D, Wynshaw-Boris A, Deng CX (2001) Direct removal in the mouse of a floxed neo gene from a three-loxP conditional knockout allele by two novel approaches. Genesis 30:1-6.

Yagi T, Nada S, Watanabe N, Tamemoto H, Kohmura N, Ikawa Y, Aizawa S (1993) A novel negative selection for homologous recombinants using diphtheria toxin A fragment gene. Anal Biochem 214:77-86.

Zheng CF, Guan KL (1993) Properties of MEKs, the kinases that phosphorylate and activate the extracellular signal-regulated kinases. J Biol Chem 268:23933-23939. 